\title{
Falsa percepção de gratuidade: a prática do zero-rating e o Marco Civil da Internet
}

\author{
False perception of gratuity: Zero-rating practice and \\ the Civil Rights Framework for the Internet
}

\author{
Hermann Bergmann GARCIA E SILVA' ID 0000-0002-0745-7308 \\ Rodrigo Moreno MARQUES 1 (D) 0000-0002-6320-4874
}

\begin{abstract}
Resumo
Diante das recentes iniciativas para eliminação, nos Estados Unidos, das regras de tratamento não discriminatório do fluxo de informações e conteúdos na Web, surgem novos desafios para a governança da Internet, notadamente no que se refere à regulação de práticas que restringem o acesso informacional dos usuários. No contexto brasileiro, o Marco Civil da Internet estabeleceu a neutralidade de rede como um princípio norteador para o uso da Internet no país, ou seja, instituiu a obrigação de tratamento isonômico dos pacotes de dados que carregam o conteúdo que circula na Internet. Nesse cenário, a presente investigação tem como objetivo confrontar a oferta de gratuidade no tráfego de dados associados a determinadas aplicações ou conteúdos, prática denominada de zero-rating, com o princípio da neutralidade de rede. Para tanto, foi desenvolvida uma pesquisa descritiva de natureza qualitativa, fundamentada em análises bibliográfica e documental. Os resultados apontam que o zero-rating não é compatível com as disposições normativas estabelecidas no marco regulatório para a Internet no Brasil. Em síntese, a pesquisa problematiza e questiona as práticas que limitam a circulação de conteúdos e inibem a liberdade de escolha dos usuários na rede mundial, confrontando-as com a governança da Internet no Brasil.
\end{abstract}

Palavras-chave: Governança da Internet. Marco Civil da Internet. Neutralidade de rede. Regulação da Internet. Zero-rating.

\begin{abstract}
In the face of recent initiatives to eliminate, in the United States, the non-discriminatory rules for the flow of information and contents through the web, new regulatory challenges arise for the governance of Internet, especially in regard to the regulation of practices that restrict the informational access of Internet users. In the Brazilian context, the Civil Rights Framework for the Internet established net neutrality as a guiding principle for Internet use in the country, that is, it instituted the obligation of isonomic treatment of data packets that carry content through the Internet. In this scenario, the present paper aims to confront the offering of Internet bundles that are free of charge for certain applications or contents, practice known as zero-rating, with the net neutrality principle. Therefore, a descriptive

\footnotetext{
1 Universidade Fumec, Programa de Pós-Graduação em Sistemas de Informação e Gestão do Conhecimento, Faculdade de Ciências Empresariais. R. Cobre, 200, Cruzeiro, 30310-190, Belo Horizonte, MG, Brasil. Correspondência para/Correspondence to: R.M. MARQUES. E-mail: <rodrigo.marques@fumec.br>.

Artigo elaborado a partir da dissertação de Garcia e Silva (2017), intitulada "Neutralidade de rede: a prática do zero-rating e o Marco Civil da Internet". Universidade Fumec, 2017.

Apoio: Fundação de Amparo à Pesquisa do Estado de Minas Gerais (Processo no APQ-02058-17), Fundação Nacional de Desenvolvimento do Ensino Superior Particular (PROPIC 2017/2017 - Edital no 01/2017) e Universidade Fumec.
}

Recebido em 2 de março de 2018, versão final reapresentada em 1 de outubro de 2018 e aprovado em 30 de outubro de 2018.
\end{abstract}

Como citar este artigo/How to cite this article

Garcia e Silva, H. B.; Marques, R. M. Falsa percepção de gratuidade: a prática do zero-rating e o Marco Civil da Internet. Transinformação, v.31, e180021, 2019. http://dx.doi.org/10.1590/2318-0889201931e180021 
research of qualitative nature was developed, based on bibliographic and documentary analyses. The results indicate that zero-rating is not compatible with the normative provisions established in the regulatory framework for the Internet in Brazil. In summary, the research problematizes and questions the practices that limit the flow of web content and prevent users' freedom of choice on the world wide web and confronts them with the Internet governance in Brazil.

Keywords: Internet governance. Civil Rights Framework for the Internet. Net neutrality. Internet regulation. Zero-rating.

\section{Introdução}

A Internet se constitui na mais profunda inovação disruptiva da história recente da humanidade, superando as mudanças promovidas com o advento da eletricidade, do motor a vapor e da telefonia. Pelas transformações ainda em curso, que transcendem a dimensão meramente econômica, pode-se considerá-la como a inovação das inovações, já que produz uma verdadeira revolução em todos os setores da sociedade, impactando de maneira significativa a organização das atividades produtivas, o modelo de negócios das empresas, a dinâmica das relações sociais, as práticas pedagógicas na educação, a estrutura do Estado e, até mesmo, os fundamentos para o exercício da cidadania.

Desde o seu início, na década de 1970, como uma rede experimental, a Internet tem apresentado um crescimento notável. Segundo estimativas da União Internacional de Telecomunicações, órgão de telecomunicações das Nações Unidas, a abrangência da Internet superou os 3,5 bilhões de pessoas em 2017, o que representa aproximadamente 47\% da população mundial (União Internacional de Telecomunicação, 2017).

Atualmente, a rede mundial de computadores conecta desde sensores a supercomputadores, com um fluxo constante de novas aplicações que tem permitido aos usuários experimentar novos conteúdos e serviços, tornando-se a principal plataforma de criação e circulação da informação e um instrumento transnacional de colaboração e interação de indivíduos e instituições.

A Internet também se materializou como uma importante ferramenta para o exercício do direito de liberdade de expressão, nos termos previstos no Pacto Internacional sobre Direitos Civis e Políticos, promulgado no Brasil pelo Decreto no 592/1992, a saber:

ARTIGO 19

2. Toda pessoa terá direito à liberdade de expressão; esse direito incluirá a liberdade de procurar, receber e difundir informações e ideias de qualquer natureza, independentemente de considerações de fronteiras, verbalmente ou por escrito, em forma impressa ou artística, ou por qualquer outro meio de sua escolha (Brasil, 1992, p.7).

No mesmo sentido, o Conselho dos Direitos Humanos da Assembleia Geral das Nações Unidas estabeleceu que "os mesmos direitos que as pessoas têm off-line deverão ser protegidos online, em particular o direito de liberdade de expressão, que é aplicável independentemente de fronteiras e através de qualquer mídia de sua escolha" (United Nations General Assembly, 2012, p.2).

É nesse contexto que a discussão em torno da neutralidade de rede ganha relevância, principalmente diante do surgimento de práticas discriminatórias de provedores de acesso à Internet que podem impactar as potencialidades da rede, por meio do bloqueio de acesso a aplicações, conteúdos ou serviços; da degradação ou do retardo intencional do tráfego; da filtragem de conteúdos; e do tratamento diferenciado a determinados provedores de aplicações e conteúdo. Entre essas práticas se insere o zero-rating, que se caracteriza como uma modalidade de discriminação por preço em que os provedores de acesso à Internet fornecem gratuidade no tráfego de dados associado a determinados conteúdos ou aplicações. 
Ressalte-se que até 2013 não havia uma clara compreensão da relação entre neutralidade de rede e a prática do zero-rating. Foi somente após a apresentação de Mark Zuckerberg, de sua nova criação, "Internet.org"2, que o assunto ganhou centralidade no universo das telecomunicações. De um lado, posicionaram-se os que alegavam que é melhor que se tenha algum acesso à Internet do que nenhum, principalmente nos mercados com menor atratividade econômica. Do outro lado, ficaram aqueles que sustentavam que a prática iria criar uma subclasse de usuários da rede mundial de computadores, sobretudo os menos favorecidos, que iriam experimentar uma rede controlada pelos detentores da infraestrutura, em prejuízo da arquitetura original da Internet de tratamento isonômico do fluxo de dados.

O Brasil assumiu um papel de protagonista nesse cenário, ao conceber um modelo de governança da Internet pautado pelo multissetorialismo e pela pluriparticipação, que possibilitou a construção e aprovação da Lei no 12.965/2014, denominada de Marco Civil da Internet (Brasil, 2014), consagrando uma regulação ex-ante ${ }^{\mathbf{3}}$ para a neutralidade de rede no país (Leite; Lemos, 2014).

Diante desse contexto, a pesquisa parte da seguinte indagação: Qual a compatibilidade da prática do zero-rating dos provedores de acesso à Internet com o princípio da neutralidade de rede, nos termos do Marco Civil da Internet vigente no Brasil? Nesse sentido, a investigação tem como objetivo confrontar o zero-rating com o princípio da neutralidade de rede, conforme estabelecido no Marco Civil da Internet Lei no 12.956/2014 (Brasil, 2014) e regulamentado pelo Decreto no 8.771/2016 (Brasil, 2016).

As análises bibliográfica e documental realizadas nesta pesquisa revelam que o Marco Civil da Internet alçou a neutralidade de rede a um patamar de princípio norteador, não franqueando a possibilidade de que práticas discriminatórias, como a do zero-rating, que colocam em risco o caráter aberto, democrático e descentralizado da rede mundial, possam trazer prejuízos à livre circulação de conteúdos na Internet e a liberdade de escolha dos usuários.

O texto está estruturado em três seções. Após a introdução, a segunda seção estabelece uma referência conceitual para o princípio da neutralidade de rede e a prática do zero-rating. Em seguida, aborda o Marco Civil da Internet e a regulamentação da neutralidade de rede, com a análise da compatibilidade do zero-rating com o marco regulatório para a Internet no Brasil. Na última seção, são tecidas algumas considerações finais sobre o resultado da pesquisa.

\section{Neutralidade de rede e zero-rating}

O termo "neutralidade de rede" foi introduzido no debate acadêmico por Tim Wu em 2003, como um princípio que busca o tratamento isonômico dos pacotes de dados, não os discriminando em razão do conteúdo (Wu, 2003). Esse conceito seguiu a lógica do princípio fim-a-fim (end-to-end), ou seja, os pacotes de dados devem fluir livremente, independentemente de seu conteúdo, desde que este seja legal, e os proprietários da infraestrutura de telecomunicações devem abster-se de tomar decisões no lugar dos usuários finais.

Ramos (2014) identifica três princípios constitutivos da ideia de neutralidade de rede, que podem ser sistematizados na obrigação imposta aos operadores da rede de não bloquear ou reduzir a velocidade de acesso de usuários a determinados conteúdos ou aplicações; na vedação de cobrança de tarifas diferenciadas para acesso

\footnotetext{
2 Em setembro de 2015, o nome da plataforma foi alterado para Free Basics. Ela é um exemplo de acesso patrocinado, por meio do qual o Facebook firma parcerias comerciais com operadoras de telecomunicações e provedores de acesso para disponibilizar aos seus usuários, sem custos de tráfego, o usufruto de um conjunto de aplicações, serviços e conteúdo que são pré-selecionados pela empresa patrocinadora. Nesse tipo de acesso, a patrocinadora arca com os custos de tráfego que são pagos às operadoras e/ou provedores de acesso (<https://info.internet.org/pt/story/platform/>).

${ }^{3}$ Conforme define Almeida (2007, p.24)"a regulação ex-ante pode ser entendida como a intervenção antecipatória, que busca promover fins socialmente desejáveis no âmbito de um determinado mercado. A regulação ex-post, por outro lado, corresponde a uma forma de reparar condutas ilícitas comprovadas por meio de uma série de medidas, incluindo multas, sanções ou vedações".
} 
a determinados conteúdos ou aplicações e na obrigação de se manter práticas transparentes e razoáveis de gerenciamento de tráfego.

Pode-se afirmar que o princípio da neutralidade de rede busca preservar os fundamentos que tornaram a Internet um instrumento de incentivo à inovação, de diminuição das barreiras de comunicação, de participação e de cooperação e de empoderamento do usuário final (Belli, 2016). Para tanto, torna como cláusula pétrea o tratamento não discriminatório do tráfego na rede, sem possibilitar que exercícios de hermenêutica, pautados por interesses econômicos, possam relativizar a autonomia conquistada pela sociedade.

Sendo assim, merece ser destacado o Decálogo de Princípios do CGI.br, que, ao tratar da neutralidade de rede, fixou a seguinte diretriz: "filtragem ou privilégios de tráfego devem respeitar apenas critérios técnicos e éticos, não sendo admissíveis motivos políticos, comerciais, religiosos, culturais, ou qualquer outra forma de discriminação ou favorecimento" (Comitê Gestor da Internet, 2009, p.2).

Nota-se que o debate acerca da neutralidade de rede está polarizado, essencialmente, em duas perspectivas de arquitetura de rede que são bem diferentes entre si.

De um lado, situa-se o modelo de manutenção da arquitetura original da Internet, que preserva as decisões na camada de aplicação, ou seja, nas extremidades da rede (pontas de origem e destino), sem intervenção do detentor da infraestrutura, o que confere maior autonomia aos usuários. Por outro lado, situam-se os defensores da necessidade de evolução da arquitetura da Internet para que ela possa suportar novos modelos de remuneração, por meio de um controle centralizado, que permita ofertar diferentes configurações de Qualidade de Serviço (QoS) ${ }^{4}$ para determinados serviços (como voz sobre IP5) ou clientes (como empresas com conexões dedicadas), priorizar o tráfego de dados por meio de vias rápidas (fast lanes) ou realizar cobranças customizadas de acordo com o perfil de uso da Internet (pay-for-play).

Braman (2011) salienta que a ausência de um regime de neutralidade de rede permite que os provedores de acesso à Internet tenham a permissão para censurar o conteúdo disponível na Internet. Na sua visão, a extraordinária diversidade de informações que circulam na rede mundial seria impactada negativamente sem a vedação ao tratamento discriminatório na Internet.

Nesse cenário atual, um tema que tem adquirido destaque é a prática do zero-rating pelos provedores de acesso à Internet, que consiste na aplicação de gratuidade no tráfego associado a uma aplicação, a um serviço ou a um conjunto de aplicações, cujo consumo de bytes não é contabilizado na franquia mensal dos contratos de acesso à Internet. A prática é um modelo diferenciado de precificação em que o custo de utilização da infraestrutura de telecomunicações é absorvido pelo provedor de acesso ou pelo provedor de conteúdo.

Em uma realidade de crescimento exponencial da demanda por dados, a disponibilidade de ofertas de zero-rating é atrativa para os usuários que atribuem valor à possibilidade de acessar determinado conteúdo ou serviço por meio de uma conexão sem cobrança, sendo que essa prática é mais utilizada pelas prestadoras de telefonia móvel.

Erhardt (2016) sintetiza as potenciais consequências do zero-rating, sobretudo sobre os excluídos da rede e menos favorecidos economicamente, nos seguintes termos:

A prática do modelo de negócios, como o acesso patrocinado ou acesso gratuito, a determinados aplicativos, ao primeiro olhar, parece um benefício ao consumidor por proporcionar um financiamento da Internet aos mais pobres.

\footnotetext{
${ }^{4}$ Qualidade de Serviço (QoS) é o “[...] conjunto de características de um serviço de telecomunicações cuja função é satisfazer as expectativas implícitas e explícitas que determinado usuário possui ao contratar um serviço de telecomunicações" (Ramos, 2015, p.18).

5 VolP - Voice over IP (voz sobre IP) é o nome dado à técnica de transmissão de tráfego de voz digital por meio de redes que empregam o protocolo IP - Internet Protocol.
} 
No entanto, a insegurança é que, em longo prazo, as barreiras de exclusão social cresçam, na medida em que os mais pobres seriam cada vez mais diferentes dos mais ricos no que se refere ao acesso de informação, ferramentas de comunicação e interação social (Erhardt, 2016, p.200).

Van Schewick (2016) entende que a prática de zero-rating distorce a competição, limita a possibilidade de escolha dos usuários, restringe a liberdade de expressão na Internet e prejudica a inovação. Para a autora, consumidores preferem utilizar conteúdos que não impactam a franquia de dados dos seus planos de serviços, motivo pelo qual as aplicações selecionadas pelos provedores de acesso desfrutam de uma vantagem competitiva sobre as demais, o que representaria uma distorção na competição do mercado. No mesmo sentido, a prática de zero-rating representa um fator determinante para a escolha de determinados conteúdos pelo usuário, o que limita a experiência da Internet. No que se refere à liberdade de expressão, à medida que se privilegiam determinados conteúdos, o zero-rating restringe o potencial da Internet de se tornar um espaço de livre participação democrática. Já o impacto negativo na inovação decorre da necessidade de adequação às condições técnicas ou comerciais que provedores de acesso à Internet irão impor às empresas que queiram integrar as suas plataformas zero-rated.

Ramos (2014) destaca que práticas de acesso patrocinado também vêm sendo realizadas com frequência em países periféricos por meio de parcerias comerciais dos provedores de conteúdo com os provedores de acesso à Internet para disponibilizar as suas aplicações sem custo de tráfego de dados para os usuários. No Brasil, são constatadas práticas de acesso patrocinado como, por exemplo, a Campanha Navegue Grátis do sítio de comércio eletrônico do Grupo Netshoes, o Navegue Grátis da loja virtual da empresa Privalia, a campanha Navegue Grátis Aplicativo Consultoria da empresa Natura, o Navegue Grátis do sítio de comércio eletrônico Mercado Livre, a Campanha Acesso Gratuito do Banco Bradesco e a Campanha Acesso Gratuito aos Aplicativos Santander do Banco Santander.

Na visão desse autor, apesar de o acesso patrocinado aparentar um benefício para o usuário final, a formatação desses planos pode impactar a concentração do mercado, restringir a inovação local, reduzir a possiblidade de escolha de conteúdos e reforçar os ciclos de dependência econômica desses países. Salienta-se que a expansão desse modelo de negócio foi possível a partir da conjugação de quatro fatores principais, quais sejam: posição dominante de grandes provedores de conteúdo; custo elevado do acesso móvel à Internet; indústria de tecnologia da informação pouco desenvolvida; debate acerca da neutralidade de rede ainda inexistente na maioria dos países.

Em 2013, a revelação de documentos sigilosos dos Estados Unidos por Edward Snowden, com o detalhamento dos diversos programas de vigilância eletrônica realizados pela NSA (National Security Agency), que atingiram, inclusive, chefes de Estado, como a ex-presidente Dilma Roussef, repercutiu em todo o mundo e demonstrou a importância de se limitar a atuação governamental e de empresas no ambiente digital, com vistas a proteger a privacidade de instituições públicas e privadas, bem como a liberdade de expressão dos cidadãos.

Uma das consequências dos graves fatos divulgados foi a retomada do debate sobre a regulação da Internet no Brasil e a imposição do regime de urgência constitucional na tramitação do Projeto de Lei no 2.126/2011 (Brasil, 2011), que se encontrava sobrestado na Câmara dos Deputados havia dois anos, no qual eram estabelecidos os princípios, as garantias, os direitos e os deveres para o uso da Internet no país.

O referido projeto foi o resultado de um amplo processo de discussão colaborativa, por meio de consulta pública online organizada pela Secretaria de Assuntos Legislativos do Ministério da Justiça, que contou com a participação de diversos atores sociais e resultou em mais de duas mil e trezentas contribuições. Lemos (2014, p.5) registra que a formatação do texto legal funcionou como "uma iniciativa pioneira na ideia de democracia expandida", já que possibilitou a contribuição direta da sociedade na sua elaboração, inaugurando um novo método de construção legislativa no país. 
Depois da aprovação pelo Congresso Nacional, da sanção presidencial e da publicação no Diário Oficial da União, a Lei no 12.965/14 (Brasil, 2014) entrou em vigor no país no dia 23 de junho de 2014, após um processo de elaboração que durou sete anos. O Marco Civil da Internet, como foi denominado, representa a consagração de um rol de princípios e normas a partir dos quais se estruturam as relações em torno da rede mundial de computadores no Brasil.

Conforme destaque do relator do projeto de lei na Câmara dos Deputados, o marco regulatório da Internet é orientado por três pilares essenciais: liberdade de expressão, privacidade dos usuários e neutralidade de rede (Molon, 2014).

Especificamente no que se refere à neutralidade de rede, o princípio foi consagrado como a obrigação de tratamento isonômico dos pacotes de dados, sem distinção por conteúdo, origem, serviço, terminal ou aplicação, conforme se observa no texto legal:

Art. 30 A disciplina do uso da internet no Brasil tem os seguintes princípios:

$[\ldots]$

IV - preservação e garantia da neutralidade de rede;

[...]

Art. $9^{\circ} \mathrm{O}$ responsável pela transmissão, comutação ou roteamento tem o dever de tratar de forma isonômica quaisquer pacotes de dados, sem distinção por conteúdo, origem e destino, serviço, terminal ou aplicação.

§1 A discriminação ou degradação do tráfego será regulamentada nos termos das atribuições privativas do Presidente da República previstas no inciso IV do art. 84 da Constituição Federal, para a fiel execução desta Lei, ouvidos o Comitê Gestor da Internet e a Agência Nacional de Telecomunicações, e somente poderá decorrer de:

I- requisitos técnicos indispensáveis à prestação adequada dos serviços e aplicações; e

II- priorização de serviços de emergência (Brasil, 2014, p.1)

Assim, segundo a Lei, tanto os provedores de acesso quanto os provedores de trânsito, que são responsáveis por operacionalizar a transmissão, a comutação ou o roteamento de dados pela rede, não podem adotar práticas discriminatórias na prestação de serviços de conexão à Internet.

Borges e Hobaika (2014) salientam que o art. 90 se aplica aos prestadores do Serviço de Comunicação Multimídia (SCM), que é o nome técnico para o serviço de telecomunicações conhecido como banda larga fixa; aos prestadores do Serviço Móvel Pessoal (SMP), que proveem banda larga móvel; e às empresas que prestam a conexão à Internet como Serviço de Valor Adicionado (SVA) ${ }^{6}$.

No referido dispositivo legal, foram previstas duas hipóteses excepcionais à neutralidade de rede, quais sejam, requisitos técnicos indispensáveis à prestação adequada de serviços e aplicações, assim como a priorização de serviços de emergência. Em ambas as situações, o responsável pela rede deve abster-se de causar danos aos usuários, deve agir com proporcionalidade, transparência e isonomia, além de informá-los, previamente, sobre as práticas de gerenciamento e mitigação de tráfego que forem adotadas.

Passados dois anos da publicação do Marco Civil da Internet, a regulamentação das exceções para o tratamento isonômico de pacotes de dados foi realizada por meio do Decreto no 8.771/2016, nos termos assim dispostos:

\footnotetext{
${ }^{6}$ De acordo com o artigo 61 da Lei no 9.472/97 (Brasil, 1997), denominada Lei Geral de Telecomunicações, o "serviço de valor adicionado é a atividade que acrescenta, a um serviço de telecomunicações que lhe dá suporte e com o qual não se confunde, novas utilidades relacionadas ao acesso,
} 
Art. $5^{\circ}$ Os requisitos técnicos indispensáveis à prestação adequada de serviços e aplicações devem ser observados pelo responsável de atividades de transmissão, de comutação ou de roteamento, no âmbito de sua respectiva rede, e têm como objetivo manter sua estabilidade, segurança, integridade e funcionalidade.

$\S 10$ Os requisitos técnicos indispensáveis apontados no caput são aqueles decorrentes de:

I - tratamento de questões de segurança de redes, como restrição ao envio de mensagens em massa (spam) e controle de ataques de negação de serviço; e II - tratamento de situações excepcionais de congestionamento de redes, como rotas alternativas em casos de interrupções da rota principal e em situações de emergência.

$[\ldots]$

Art. $8^{\circ}$ A degradação ou a discriminação decorrente da priorização de serviços de emergência somente poderá decorrer de:

I - comunicações destinadas aos prestadores dos serviços de emergência, ou comunicação entre eles, conforme previsto na regulamentação da Agência Nacional de Telecomunicações - Anatel; ou

II - comunicações necessárias para informar a população em situações de risco de desastre, de emergência ou de estado de calamidade pública.

Parágrafo único. A transmissão de dados nos casos elencados neste artigo será gratuita (Brasil, 2016, p.2).

Como se observa, os requisitos técnicos indispensáveis à prestação adequada de serviços e aplicações, que foram especificados como exceção à regra de tratamento não discriminatório, são aqueles que decorrem da necessidade de se implementar medidas de segurança de rede ou nas situações excepcionais de congestionamento da rede.

Por conseguinte, não há, no texto normativo, nenhuma referência à possibilidade de um tratamento diferenciado para a discriminação por preço. Apesar de não fazer referência expressa à prática do zero-rating, o Decreto regulamentador do Marco Civil da Internet vedou, no artigo 9, os acordos comerciais entre provedores de acesso e provedores de conteúdo da seguinte maneira:

Art. $9^{\circ}$ Ficam vedadas condutas unilaterais ou acordos entre o responsável pela transmissão, pela comutação ou pelo roteamento e os provedores de aplicação que:

I - comprometam o caráter público e irrestrito do acesso à internet e os fundamentos, os princípios e os objetivos do uso da internet no País;

II - priorizem pacotes de dados em razão de arranjos comerciais; ou III - privilegiem aplicações ofertadas pelo próprio responsável pela transmissão, pela comutação ou pelo roteamento ou por empresas integrantes de seu grupo econômico (Brasil, 2016, p.2).

Registre-se que o Inciso I impõe a vedação de qualquer conduta ou acordo entre provedores de acesso, provedores de trânsito e provedores de conteúdo que comprometa os fundamentos, princípios e objetivos do uso da Internet no Brasil. 
Já o Inciso II estabelece de maneira específica a impossibilidade de priorizar o tráfego da Internet em virtude de arranjos comerciais. Importante salientar que, segundo essa interpretação da lei, estão vedadas tanto a discriminação por velocidade quanto a discriminação por preço, já que o fato de aplicações zero-rated não serem submetidas ao bloqueio ou à redução da velocidade de acesso, quando se alcança o limite de dados contratados, caracteriza uma priorização de pacotes de dados em razão de acordos comerciais entre o provedor de conteúdo e o provedor de acesso à Internet.

Nessa perspectiva, Oliveira (2014) destaca a incompatibilidade do zero-rating com o princípio da neutralidade de rede:

A oferta gratuita de acesso a determinada aplicação é uma estratégia de marketing, pois evidentemente tanto o provedor de conexão, que amplia sua base de usuários e o volume de tráfego por suas redes, quanto o provedor de aplicações, que incrementa o potencial publicitário de seu serviço, têm benefícios econômicos indiretos por essa oferta.

Ocorre que, ao estimular o acesso a determinada aplicação (como o Facebook), o provedor de conexão viola o princípio da neutralidade de rede, pois privilegia o conteúdo de uma aplicação em detrimento de outro, redirecionando (ou estimulando o redirecionamento) do internauta a determinada aplicação.

Ora, por que o provedor de aplicação só dará privilégio a uma determinada aplicação (como o Facebook) em detrimento de outra (como o Orkut)? Isso não é admitido (Oliveira, 2014, p.8).

Björksten, Chima e Massé (2016) vão além e consideram que a prática do zero-rating representa uma antítese à neutralidade de rede, nos seguintes termos:

Zero-rating é o oposto da neutralidade de rede, a noção que todos os dados na Internet devem ser tratados de maneira isonômica. A neutralidade de rede é fundamental para manter o potencial de desenvolvimento econômico e social da Internet, e para o exercício de direitos humanos reconhecidos intencionalmente, como o direito à liberdade de expressão. Seus princípios ajudam a garantir que qualquer pessoa, em qualquer lugar do mundo, possa receber e transmitir informações livremente pela Internet, não importa onde estejam, quais serviços utilizem, ou quais dispositivos operem. Nessa perspectiva, o zero-rating é uma forma de discriminação na rede, que deliberadamente configura um sistema em que a Internet que você obtém é diferente para pessoas diferentes (Björksten Chima e Massé, 2016, p.106, tradução nossa).

Ou seja, a priorização de pacotes não pode ser interpretada de forma restritiva, considerando apenas a modalidade de discriminação por velocidade, já que a prática de zero-rating, seja por meio do acesso patrocinado pelo provedor de conteúdo ou por iniciativa do próprio operador da rede, também prioriza os datagramas, ao atribuir gratuidade para alguns tipos de tráfego de dados na Internet.

Conforme já exposto, segundo a lei brasileira, as únicas exceções possíveis ao princípio da neutralidade de rede estão relacionadas tão somente a aspectos de ordem técnica ou à priorização dos serviços de emergências, o que indica a incompatibilidade das práticas de discriminação por preço com o Marco Civil da Internet.

No artigo 10, ficou estabelecido que "as ofertas comerciais e os modelos de cobrança de acesso à Internet devem preservar uma Internet única, de natureza aberta, plural e diversa [...] contribuindo para a construção de uma sociedade inclusiva e não discriminatória" (Brasil, 2016, p.3). Em regra, as práticas comerciais de isenção tarifária 
pelos provedores de acesso estariam em discordância com a disciplina da Internet no Brasil, independentemente do seu rótulo comercial. Isso porque o zero-rating constitui uma modalidade de discriminação por preço que influencia diretamente a escolha dos usuários, possibilitando a criação de subdomínios privados na rede mundial de computadores que seriam definidos de maneira unilateral pelos detentores da infraestrutura de telecomunicações, em prejuízo da arquitetura original da Internet, que estabelecia uma rede aberta e pautada pela livre circulação da informação e do conhecimento (Belli, 2016).

\section{Considerações Finais}

No Brasil, o Marco Civil da Internet definiu a neutralidade de rede como um dos seus pilares essenciais, estabelecendo a obrigação de tratamento isonômico dos pacotes de dados, sem distinção por conteúdo, origem, serviço, terminal ou aplicação, sendo que as únicas exceções possíveis ao princípio estão relacionadas com aspectos de ordem técnica ou à priorização dos serviços de emergências.

Portanto, a presente investigação aponta que o zero-rating está em discordância com as disposições normativas estabelecidas no Marco Civil da Internet e na sua recente regulamentação, já que o marco regulatório para a Internet no país definiu de maneira bem específica quais seriam as hipóteses excepcionais ao tratamento não discriminatório na Internet, o que não incluiu as modalidades de discriminação por preço, entre elas a prática do zero-rating.

Há que se salientar que a coexistência do zero-rating com uma estrutura normativa que estabelece a neutralidade de rede revela uma realidade paradoxal, já que ambos representam valores antagônicos. De um lado são previstas garantias para um ambiente livre, aberto e democrático na Internet, com o tratamento isonômico e não discriminatório do tráfego de dados, enquanto do outro se busca privilegiar o acesso a conteúdos pré-selecionadas pelos provedores de acesso à Internet, restringindo a experiência, a autonomia de escolha e o fluxo de informações na rede mundial.

A falsa percepção de gratuidade, associada ao fato dos usuários acessarem determinado conteúdo ou serviço por meio de uma conexão sem cobrança, ofusca os reais interesses do zero-rating que estão relacionados com o aumento da receita advinda da ampliação da base de clientes, do aumento da participação no mercado e do incremento das receitas por meio dos contratos com os provedores de conteúdo. De outra maneira, não haveria justificativa econômica para que os provedores de acesso ou os provedores de conteúdo subsidiassem os custos de utilização da infraestrutura de telecomunicações dos usuários.

Por conseguinte, evidencia-se uma manifesta contradição entre um marco regulatório que estabelece como princípio o tratamento não discriminatório na Internet e que admite uma interpretação que não coibi o zero-rating, já que esse tipo de prática, em sua essência, confere tratamento diferenciado a determinadas aplicações e conteúdos.

À vista disso, a regulamentação da neutralidade de rede nas políticas de informação nacionais é de fundamental importância para garantir que as decisões sobre a estrutura da Internet possam incorporar a utilização da informação e do conhecimento como elementos que reduzam as desigualdades socioeconômicas e contribuam para a emancipação humana.

\section{Colaboradores}

Ambos os autores participaram ativamente, em regime de colaboração, de todas as etapas da construção do artigo, desde a sua concepção, análise e interpretação dos dados, até a revisão da versão final do texto. 


\section{Referências}

Almeida, G.A.A. Neutralidade da rede e desenvolvimento: o caso brasileiro. Malta: Diplo Foundation, 2007. p.24.

Belli, L. Net neutrality, zero rating and the minitelisation of the Internet. Journal of Cyber Policy, v.2, n.1, p. 96-122, 2016.

Björksten, G.; Chima, R.J.S.; Massé, E. Zero rating: A global threat to the open Internet. In: Belli, L. (Ed.). Net neutrality reloaded: Zero rating, specialized service, ad blocking and traffic management. Rio de Janeiro: Fundação Getúlio Vargas, 2016. p.106-116.

Borges, L.C.C.; Hobaika, M.B.S. Responsabilidade jurídica pela transmissão, comutação ou roteamento e dever de igualdade relativo a pacotes de dados. In: Leite, G.S.; Lemos, R. Marco Civil da Internet. São Paulo: Atlas, 2014. p.651-676.

Braman, S. Internet policy. In: Consalvo, M.; Ess, C. (Org.) The handbook of internet studies. Chicheste: Blackwell Publishing, 2011. p.137-167.

Brasil. Congresso Nacional. Projeto de Lei no 2.126, de 2011. Estabelece princípios, garantias, direitos e deveres para o uso da Internet no Brasil. Disponível em: <http://www.camara.gov.br/ proposicoesWeb/fichadetramitacao?idProposicao=517255>. Acesso em: 30 ago. 2017

Brasil. Presidência da República. Decreto n 592, de 6 de julho de 1992. Promulga o Pacto Internacional sobre Direitos Civis e Políticos. Diário Oficial da União, Brasília, 1992. Disponível em: <http://www.planalto.gov.br/ccivil_03/decreto/1990-1994/ d0592.htm>. Acesso em: 30 ago. 2017.

Brasil. Presidência da República. Lei no 9.472, de 16 de julho de 1997. Dispõe sobre a organização dos serviços de telecomunicações, a criação e funcionamento de um órgão regulador e outros aspectos institucionais, nos termos da Emenda Constitucional no 8, de 1995. Diário Oficial da União, Brasília, 1997. Disponível em: <http://www.anatel.gov.br/ legislacao/leis/2-lei-9472\#livrol>. Acesso em: 10 nov. 2018.

Brasil. Presidência da República. Lei no 12.965, de 23 de abril de 2014. Estabelece princípios, garantias, direitos e deveres para o uso da Internet no Brasil. Diário Oficial da União, Brasília, 2014. Disponível em: <http://www.planalto.gov.br/ ccivil_03/_ato2011-2014/2014/lei/l12965.htm>. Acesso em: 30 ago. 2017.

Brasil. Presidência da República. Decreto no 8.771, de 11 de maio de 2016. Regulamenta a Lei no 12.965, de 23 de abril de 2014. Diário Oficial da União, Brasília, 2016. Edição Extra. Disponível em: <http://www.planalto.gov.br/ccivil_03/_
Comitê Gestor da Internet. Princípios da governança e uso da Internet no Brasil. São Paulo: CGI.br, 2009.

Garcia e Silva, H.B. Neutralidade de rede: a prática do zerorating e o Marco Civil da Internet. Dissertação (Mestrado em Sistemas de Informação e Gestão do Conhecimento) Universidade Fundação Municipal de Educação Comunitária, Belo Horizonte, 2017.

Erhardt, A. A prática do Zero Rating e o Princípio da Neutralidade de Rede previsto na Lei no 12.965/14: reflexões sobre o fenômeno da inclusão digital e o desenvolvimento de novas tecnologias. Revista de Direito, Estado e Telecomunicações, v.8, n.1, p.193-207, 2016.

Leite, G.S.; Lemos, R. (Org.). Marco Civil da Internet. São Paulo: Atlas, 2014. p.200.

Lemos, R. O marco civil como símbolo do desejo por inovação no Brasil. In: Leite, G.S.; Lemos, R. (Org.). Marco Civil da Internet. São Paulo: Atlas, 2014. p.3-11

Molon, A. Congresso Nacional. Relatório final do Projeto de Lei no 2.126, de 2011. Brasília, 2014. Disponível em: <https:// www.camara.gov.br/proposicoesWeb/prop_mostrarintegra? codteor=1012195>. Acesso em: 30 ago. $201 \overline{7}$.

Oliveira, C.E.E. Aspectos principais da Lei no 12.965, de 2014, o Marco Civil da Internet: subsídios à comunidade jurídica. Brasília: Senado Federal, 2014. p.8.

Ramos, P.H.S. Towards a developmental framework for net neutrality: The rise of sponsored data plans in developing countries. In: Telecommunications Policy Research Conference, 42., 2014, Arlington. Anais [...] Arlington: George Mason University, 2014. p.1-25.

Ramos, P.H.S. Arquitetura da rede e regulação: a neutralidade da rede no Brasil. 2015. 218f. Dissertação (Mestrado em Direito) Fundação Getúlio Vargas, São Paulo, 2015.

União Internacional de Telecomunicações. Key 2005-2017 ICT data for the world. Genebra: UIT, 2017.

United Nations General Assembly. A/HRC/20/L.13, 29 June 2012. The promotion, protection and enjoyment of human rights on the Internet. 2012. Available from: <https:// documents-dds-ny.un.org/doc/UNDOC/LTD/G12/147/10/ PDF/G1214710.pdf?OpenElement>. Cited: Aug. 30, 2017.

Van Schewick, B. T-mobile's binge on violates key net neutrality principles: Report. Stanford: Stanford Law School's Center for Internet and Society, 2016.

Wu, Tim. Network neutrality, broadband discrimination. Journal of Telecommunications and High Technology Law, v.2, p.141-179, 2003. 